\title{
Factors That Affect User Satisfaction Of Electronic Learning Management Systems (ELMSs)
}

\author{
Riyadi $^{\text {a }}$, Umar Nimran ${ }^{\text {a }}$, Eko Ganis Sukoharsono ${ }^{a}$, Muhammad Al Musadiq ${ }^{a}$ \\ ${ }^{a}$ University of Brawijaya, Malang, Indonesia
}

\section{ARTICLE INFORMATION}

\section{Article history:}

Data submission : 28 October 2019

$1^{\text {st }}$ revision: 13 December 2019

Accepted: 1 January 2020

Available online: 3 February 2020

Keywords: ELMSs; Subjective norms; Satisfaction and perceived innovation
ABSTRACT

This research intends to explore a variety of factors that may affect the satisfaction use of ELMSs. Therefore, various factors have been tested empirically by using another model approach integrated into a single model. Other variables that are still reliable for further research without changing the construct of the indicators are subjective norms, usability, perceived innovation and satisfaction. Some relationships between variables that have significant influence include usability on perceived innovation, perceived innovation on satisfaction. One relationships between variables that have a small influence subjective norms on perceived innovation.

2020 FIA UB. All rights reserved.

\section{Introduction}

Since then e-learning has been defined as a learning activity that uses networks (Internet, LAN, WAN) as a method of delivery, interaction and facilitation and is supported by various other forms of learning services (Brown, 2000). According to Wulf (1996) the benefits of electronic learning consist of four things:

(1). The increased level of learning interaction between students and teachers or lecturers (increasing interactivity).

(2). Allows learning interaction anywhere and anytime (flexibility of time and place).

(3). Reaching students in scope (potential to reach a global audience).

(4). Facilitating the improvement and storage of teaching materials (easily updating content and archive capabilities).

In business organizations, adopting an e-learning system aims to increase investment returns, reduce travel costs, help workforce planning, and provide content without sacrificing quality. With online classes making easy access to employee desktops, so a tailored learning system can increase organizational productivity (Kirkpartick, 1998). The survey was conducted to the trainees through e-learning, the training evaluator provided information about the factors of satisfaction in the online course. In addition, successful training evaluations can produce effective and efficient organizations.

The results of research in the academic world also show positive things. Participants learn online with higher participation rates than conventional classes. However, in addition to positive responses and success stories, e-learning also failed. Chau and $\mathrm{Hu}$ (2001) in a paper entitled "The future of e-learning as an educational innovation: Factors that influence the success and failure of a project", explain the important factors for the success and failure of e-Learning adoption. In general, whatever the field of technological innovation, the process always follows a theoretical trajectory that is when there is enthusiastic acceptance it is usually followed by widespread rejection. This phenomenon also appears in e-learning as an innovation, and such tendencies emerge in the "first adopters" leading countries such as the United States and European countries. Therefore they warn that other countries that adopt e-learning in time can avoid the mistakes of the first country.

From the beginning until 2002, e-learning has experienced skyrocketing popularity, but then it was

* Corresponding author. Tel.: +62-821-55136-363; e-mail: riyadi@ub.ac.id 
followed by a drastic failure. The e-learning phenomenon is very similar to Television Broadcast Education in Latin America in 1960-1980. Growth peaked in the mid-1970s, after which it continued to decline into the 1980s. As an innovation in education, elearning experiences problems in the continuation of the process after initial adoption.

When e-Learning experienced a crisis that resulted in failure, a 2000 study conducted by the Forrester Group of 40 large companies showed that most workers (more than $68 \%$ ) refused to participate in training / courses using the concept of e-Learning. When e-Learning is required of them, around $30 \%$ of workers refuse to participate. Meanwhile, other research shows that of those who register for e-Learning, 50-80\% never finish until the end (Keil et al. 1995).

Now the number of LMS service provider sites is increasing and varied. Each offers various advantages that it has. What needs to be emphasized here is the increasing number of users of LMS websites only illustrates the growth in the number of initial users who are expanding sites around the world. As for how the implementation process and user behavior in the LMS, the statistical report does not provide a description. Warning Kumar et al (1996) so that other countries will adopt e-learning in a short time later, to avoid the mistakes of the first countries seems still relevant to note. Because the opportunities for early adopter behavior of other countries that are new to LMS are very likely to have similarities with the pattern that occurred in the US about 10 years ago.

So when taking reflection adopting the e-learning experience as an educational innovation, from the initial growth of the country of origin to the spread throughout the world, including in Indonesia, the main problem is the continuation of the use of post-adoption or implementation. Because the initial investment in elearning technology is generally not small, if it is not utilized or even terminated, it is clearly a big loss. Therefore, the course of research on the use of elearning continues to be carried out using various modeling approaches. Of course the expected goal is to explore the possibilities of new findings that are useful as solutions to the continued problem of e-learning implementation.

The current literature review shows that there are three basic models used by researchers to find answers to research questions related to the success of an information system. These models include the work of TAM from Davis (1989), The Theory of Confirmation of Hope (ECT), which developed into the Confirmation Model of the Information Technology Model (ECM IT) by Bhattacherjee $(2000,2001)$ and the Information System Success Model for working with DeLone and McLean (1992) in 2003.

In the process, these models are combined by other researchers with the aim of obtaining new models that can provide a more satisfying explanation. This is done because three basic models on the way have found various limitations of the gap. The researchers combine the basic model with various factors, hoping to eliminate some of the limitations of certain models. In addition, various causative factors have also been expanded to explore their role in contributing to the success of information systems.

In the development more and more researchers are testing the model it is known that by applying it to different conditions. The hope is that under different conditions, whether the results still show a fixed or changing trend of conclusions. However, not a few researchers who design by modifying and combining the models above, even with the addition of several decision variables. This new model was designed with the hope of being able to better explain the intention to use sustainable LMS technology.

\section{Theory}

\subsection{Learning Management System (LMS)}

Advances in information and communication technology (ICT) have enabled many things to be done. In education today ICT has been used to support teaching and learning in the form of e-learning and to improve the management of educational administration in the form of academic information systems. E-learning is one form of application of ICT in education, which is oriented to the use of information technology to meet learning needs. So e-learning allows people to study anywhere at any time. Another advantage is the use of less time. Therefore, the existence of e-learning is considered as a learning solution that can be adopted according to various learning needs.

LMSs offer innovative virtual learning through webbased online learning, multimedia, and video conferencing. The elements incorporated into the development of LMS are designed to harmonize the development of psychology students. These elements are related to real life, the approach is indirect, pleasant, positive reinforcement and accommodates search.

There are several important things because the requirements for learning software can be referred to as e-learning, namely; (1) learning activities are carried out through the use of the internet network. (2) providing support learning services that can be used by participants to learn, such as CD-ROMs, modems, flash drives, printers, cameras (3) Availability of tutor support services that can help participants learn when experiencing difficulties. (4) Providers who manage eLearning activities. (5) Positive responses from students and staff, (6) learning system designs that can be learned by each participant for learning, (7) progress evaluation or learning development systems and (8) feedback mechanisms developed by providers (Kamil, 2010). From the description above it can be concluded that eLearning is a learning activity that utilizes the Internet as a method of delivery, interaction and facilitation and is supported by various other forms of learning services. The term e-learning or Learning Management System is often used interchangeably, understanding the essence is the same. 


\subsection{E-Learning as an Innovation in Education}

In the field of education, many businesses or activities are aimed at increasing education reform. Innovations that occur in the education sector include learning management, learning methodologies, media, learning resources, lecturer training, curriculum implementation, and so on. When viewed from several aspects, it can be said that e-learning innovation is not only on teaching methods.

\subsection{Subjective Norms ( $S N)$}

The decision will be taken to display certain behaviors to someone that can be done with his own judgment and based on the consideration of others who are considered important. The decision chosen may fail if others' considerations are not supportive, even though personal considerations suggest. Thus, the subjective judgment of others can influence to do something.

Fishbein and Ajzen (1976) argue that "Subjective norms are people's perceptions that most people who are important to him think he should or may not conduct the behavior in question." about people's expectations about influential people (other important) either individuals or social groups to display certain behaviors or not. So Subjective Norms are individual perceptions about other people's expectations of individuals. .

Subjective norms or social influences have an impact on individual behavior through three mechanisms. There are three mechanisms of social influence are. First, compliance is a condition that occurs when someone is influenced by a person or group. He wants to get a gift or avoid punishment from party influence. Someone who accepts the recommended behavior not because of trust, but because such behavior helps him get a satisfying social effect from the environment. For example, a student must obey a lecturer's command not to bring a cellphone to the classroom. Compliance occurs because students avoid sanctions.

Second, identification is a condition that occurs when individuals take behavior that comes from other people or groups, taking into account the impact of the behavior will provide satisfaction to the social environment in which people interact. For example, someone tries to learn and use the social networking site Facebook, because all his friends often communicate through face books. So his action is an effort to align himself with the social environment.

Third, internalization is the process that occurs when people receive influence because it is recommended practice in accordance with the value system. Someone accepts ideas, thoughts or suggestions from others, because their ideas, thoughts or suggestions are considered reasonable by the individual concerned and are considered useful for solving problems, or important in showing direction, or indeed in harmony with the value of individual systems. For example, someone reads an opinion in the media stating that today is an age where one must be able to use information technology for the purposes of daily life. People agree that because of their own experience, people often encounter many obstacles to overcome problems in life.

According to Fishbein and Ajzen (1976), subjective norms generally have two components, namely normative beliefs and motivation to obey. First, normative beliefs are beliefs related to opinion leaders or other people that are important and influential for individuals or role models whether the subject must perform certain behaviors or not. Second, motivation to comply is the motivation of individuals to meet the perception of public opinion, the media or the people around him with the motivation to follow his views whether or not to conduct certain behaviors.

In the decomposed TPB model, subjective norms are explained in the two dimensions of Peer influence and Superior influence. But in the model developed by Butler and Sellbom (2002), peer influence and Superior influence are classified as interpersonal influences, then add the influence of external factors related to the influence of mass media, public opinion, science reports. In Rogers innovation diffusion theory subjective norms are strongly related to social structure, social norms, influential leaders, agents of change (Rogers and Floyd, 1971).

\subsection{Usability $(U)$}

The definition of usability according to ISO 9126 is the ability of software to be understood, studied, used, and attractive to users. From this definition it can be operationalized that usability is a variety of factors which indicate that e-learning can generate interest, be understood and used. Usability is translated into four dimensions, namely Understandability, Learnability, Operability, and Attractiveness. The elaboration dimension of the use of construct indicators is to adapt the J.R questionnaire. This questionnaire was published in the IBM Computer Satisfaction Questionnaire paper: Psychometric Evaluation and Instructions for Use.

Understood, which is a measure of ease of understanding, in my opinion:

(1). Information and instructions provided in e-learning are very easy to understand.

(2). Information and instructions provided in e-learning effectively to help complete the task.

(3). The layout of the information and instructions displayed on the e-learning screen is very clear.

Learnability, which is a measure of learning ease:

(1). It's easy to learn using e-learning.

(2). I am sure it will be more productive when using elearning.

(3). The error message given by e-learning explains clearly how to overcome it.

(4). Every time I make a mistake, I can fix it quickly and easily.

(5). Information and instructions provided by e-learning are quite clear.

(6). It's easy to find the information needed in elearning.

Operability, which is a measure of ease of use.

(1). Overall, I am satisfied with the ease of use of elearning. 
(2). The use of e-learning is very simple.

(3). By using e-learning, I can complete the job perfectly.

(4). By using e-learning, I can finish my work quickly.

(5). By using e-learning, I can finish my work efficiently.

(6). I feel comfortable using e-learning.

Attraction is a measure of attractiveness to generate interest in using.

(1). Show the fun of e-learning.

(2). I like to use e-learning to look like this.

(3). The e-learning feature has functions and abilities as I expected.

(4). The display of e-learning supports the objectives and learning methods.

(5). Overall, I am satisfied with e-learning performance.

\subsection{Perceived Innovation (PI)}

Defined by Rogers (1983) as an idea, practice, or object that is considered / just felt by an individual. In the context of e-learning research the definition is operationalized as the perception that individuals are associated with more value e-learning compared to conventional learning, as measured by innovation attributes; relative superiority, compatibility, complexity, trial ability, and observation ability. But for the context of innovation in information technology (including e-learning) by Karahana, et al (1999) translated into perceptions of usability, images, compatibility, ease of use, testability, visibility and demonstration of results. By adapting the dimensions of innovation developed by Karahana, et al (1999and the elaboration of innovation indicators by I.M.

The relative advantage or perceived benefits, is the extent to which adopting/using IT innovation is considered better than the practice it replaces.

The experience was tried several times, showing:

(1). E-learning facilitates the implementation of the learning process

(2). E-learning to improve the quality of the learning process.

(3). E-learning makes the learning process more effective

(4). E-learning increases my teaching productivity.

(5). E-learning is more fun to plan learning.

Image, is the extent to which adopting / using IT innovation is felt to enhance one's image or the status of one's social system.

By using e-learning:

(1). My image as a professional lecturer can be improved.

(2). I want to be perceived as a lecturer who always follows the development of science and technology.

(3). I hope to increase my career growth.

(4). Compatibility is the extent to which IT innovation is compatible with what people do.

The experience was tried several times, showing:

(1). E-learning can be used in all fields of learning

(2). E-learning is in accordance with the learning method that I use

(3). E-learning is in accordance with my teaching style in learning activities

(4). E-learning supports the learning objectives in the curriculum / syllabus.

\subsection{Satisfaction $(S)$}

Satisfaction can be defined as feeling happy or like when someone does something or get something desired. When used in this study, satisfaction is conceptualized as a group of people's feelings or attitudes towards many factors that influence a particular situation. Sense of satisfaction in the context of Expectation Confirmation Theory defined by Oliver et al. (1985) is an unpleasant or positive emotional state, which results from evaluating the performance of a product or service.

Satisfaction is seen as the key to building and maintaining a loyalty base for long-term use. Satisfaction is a psychological state that is related to what is expected from the difference in performance expectations. If performance expectations are lower and higher then confirmation is greater, which in turn affects user satisfaction and intention to pursue. Meanwhile, when the reverse occurs, it causes disconfirmation, dissatisfaction and an intention to stop it.

Exploring satisfaction in various research literature, finding various dimensions and indicator variables expressing satisfaction of each researcher. The translation of satisfaction is often associated with the object of research. The result is that satisfaction indicators vary and because there are no standard measures. Satisfaction dimension which consists of; content, accuracy, format, ease of use, and timeliness. Three dimensions of user satisfaction variables, namely efficiency, effectiveness and satisfaction. DeLone \& McLean (2003) describes User Satisfaction with dimensions: Repeated purchases, Repeat visits, and user surveys. Bhattacherjee (2001) uses the overall satisfaction criteria. Other researchers have linked with service quality, so that the dimensions used are tangible, reliability, responsiveness, assurance, and empathy.

\section{Research Method}

This research is designed to answer the problems that have been formulated, the research objectives, and to test hypotheses using a quantitative approach. This research is an explanatory study, a research that seeks to explain the relationship between variables through hypothesis testing. Based on the data collected, this research is included in the type of survey research.

Departing from the research model designed in the Theoretical Framework, the explanation of the research variables and building indicators are as follows. Subjective Norms (NS) are media / internet, social structure, social norms, heads of organizations / institutions / departments, experts in IT and colleagues who influence the adoption of the use of e-learning to individuals. Indicators of Subjective Norms (SN) are:

(1). X1.1 Opinions in the mass media or on the internet encourage the use of e-learning.

(2). X1.2 As a lecturer, the work environment pressures me to use e-learning. 
(3). X1.3 It is imperative for lecturers to adjust to the latest teaching methods.

(4). X1.4 The leaders in my educational institution encourage the use of e-learning.

(5). X1.5 The opinions of IT experts support the use of positive e-learning.

Usability (U) are various factors that show that elearning can generate interest, be understood, studied and used. Usability Indicators (U) are:

(1). X2.1 In my opinion: Information and instructions provided in e-learning are very easy to understand.

(2). X2.2 In my opinion: Information and instructions provided in e-learning are effective to help complete the task.

(3). X2.3 In my opinion: The layout of the information and instructions displayed on the e-learning screen is very clear.

(4). X2.4 It's easy to learn using e-learning.

Perception of Innovation (PI) is felt by individuals associated with the value of more e-learning compared to conventional learning, as measured by the attributes of innovation. Indicators of Innovation Perception (PI) are:

(1). Y1.1 Experience is tried several times, showing: elearning facilitates the implementation of the learning process

(2). Y1.2 Experience has been tried several times, showing: e-learning to improve the quality of the learning process.

(3). Y1.3 Experience has been tried several times, showing: e-learning makes the learning process more effective

(4). Y1.4 Experience has been tried several times, showing: e-learning increases my teaching productivity.

(5). Y1.5 The experience of trying several times, shows: e-learning is more fun to plan learning.

(6). E-learning can be used in all fields of learning

(7). E-learning is in accordance with the learning method that I use.

Satisfaction (KP) can be operationalized into a fun or positive emotional state of e-learning users after seeing the benefits and abilities of e-learning. Satisfaction Indicators are:

(1). Y4.1 Overall I am satisfied with the learning process that I manage with e-learning.

(2). Y4.2 Overall I am satisfied with the quality of the learning outcomes that I manage with e-learning.

(3). Y4.3 I like and enjoy interacting with e-learning.

Likert scale derived from the name Likert (1932) is used to measure social phenomena, social phenomena research is specifically determined by researchers, hereinafter referred to as research variables. With a Likert scale, the variables to be measured are translated into dimensions. Then the dimensions are translated into indicators that can be measured. These indicators are in the form of questions or statements answered by respondents. The form of the scale in the questionnaire used in this study uses a Likert scale with a standard scale of 1 to 7 . Each respondent is asked to provide an assessment question with a choice of Likert scale answers as follows:

(1) Strongly disagree: score 1

(2) Disagree: score 2

(3) Less agree: score 3

(4) Neutral: score 4

(5) Somewhat agree: score 5

(6) Agree: a score of 6

(7) Strongly agree: score 7

The number of samples in this study, according to the analysis plan, is based on the opinion of Hair, et al., (1992), that the minimum appropriate sample size in the study is a minimum of 100 respondents. Based on that opinion, the number of respondents used in this study is at least 100 staffs of Malang State University (UM).

\section{Results}

In this study of the total sample selected 100 , there were 57 people selected men $(57 \%)$ and 43 people selected were women $(43 \%)$. In accordance with the framework of the concept of research and the image of research hypotheses, the number of observed variables or the number of latent / contract variables are 8 , and the total indicators are 19 questions (19 manifest variables). The eight constructs include the Subjective Norms $(\mathrm{SN})\left(\mathrm{X}_{1}\right)$ variable consisting of 5 questions, the Usability $(\mathrm{U})\left(\mathrm{X}_{2}\right)$ variable consists of 4 questions, the Perceived Innovation (PI) (Y1) variable consists of 7 questions, and the Satisfaction (S) variable) (Y2) While the calculation of data analysis in this study uses the SmartPLS 3.2.8 software. The results of calculations on the construct validity and reliability tests are shown in Figure 1 and Figure 2, which are the results of running on the outer model test (measurement model).

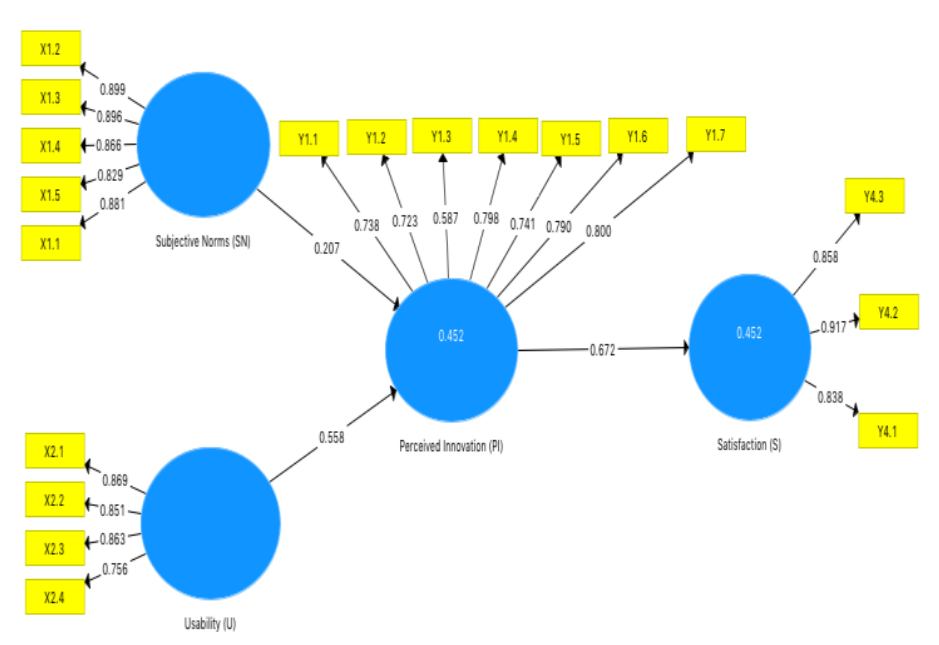

Figure 1. Construct validity

Figure 1 shows that the results of the construct validity and reliability tests. In the validity test questions or indicators that indicate the value of the loading factor $<0.7$ will be excluded from the model (Hair at.al., 2014: 
103). In Figure 5.6, the first output running shows the loading factor $<0.7$ and then it will be removed from the model one by one, including $\mathrm{Y}_{1.3}=0.6630 .692$. After running four times and finally obtained an external model that has loaded all the indicators with the loading factor value $>0.7$. This means that all indicators have been accepted valid.

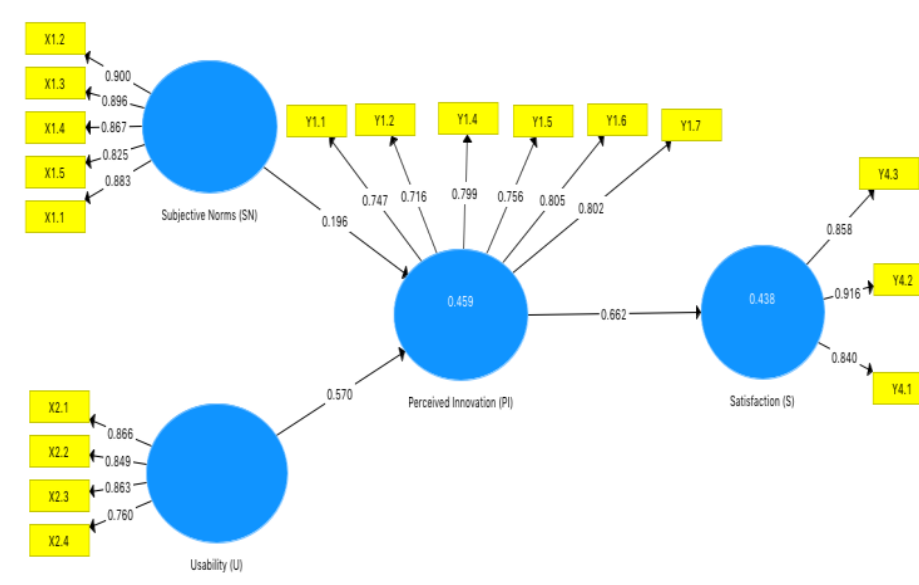

Figure 2. Loading factor results

Figure 2 shows the loading factor value $>0.7$ for each indicator in each latent / construct variable means that the SEM model has been composed of indicators that are all valid. In addition to the loading factor value, there is a cross-loading value that can be used to analyze the validity of indicators. An indicator is said to be valid if the value of cross loading <loading factor (Hair at.al., 2014: 111-112).

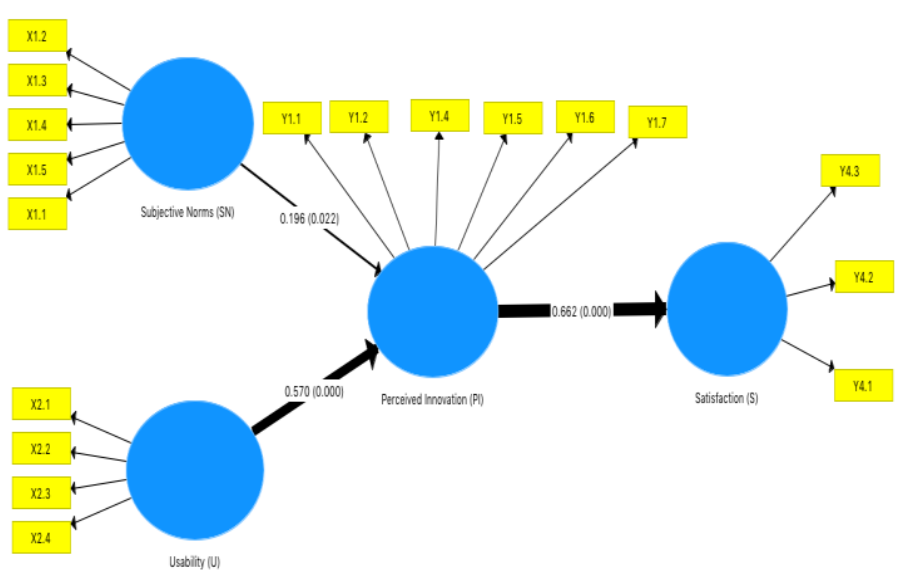

Figure 3. Final model

Figure 3 explains the results of Bootstrapping calculations to test the inner model that describes the research hypotheses in the final SEM model simultaneously. The final results of the path analysis that explain the direct Influence (direct Influence) from construct to construct include successively as follows:

(1). Subjective Norms $(\mathrm{SN})\left(\mathrm{X}_{1}\right)$ have a samll influence on Perceived Innovation (PI) ( $\left.\mathrm{Y}_{1}\right)$ with a path coefficient that is $\mathrm{pY}_{1} \mathrm{X}_{1}=0.196$ and $\mathrm{p}$-value $=$ 0.022 . So the first hypothesis is accepted.
(2). Usability (U) $\left(\mathrm{X}_{2}\right)$ has a significant influence on Perceived Innovation (PI) ( $\left.\mathrm{Y}_{1}\right)$ with a path coefficient that is $\mathrm{pY}_{1} \mathrm{X}_{2}=0.570 \mathrm{p}$-value $=0.000$. So the second hypothesis is accepted.

(3). Perceived Innovation (PI) $\left(\mathrm{Y}_{1}\right)$ has a significant influence on Satisfaction (S) (Y2) with a path coefficient that is $\left.\mathrm{pY}_{3} \mathrm{Y}_{1}=0.7190 .667\right)$ and $\mathrm{p}$-value $=0.000$. So the third hypothesis is accepted.

\section{Discussion and Conclusion}

The results of the suitability of the final model that prove the influence of even though a small variable Subjective Norms to Perception of Innovation is the finding that the diffusion process of e-learning innovations that occur due to the influence of the social system turns out to exist even though it is weak. The findings of this study reinforce Rogers's (1983) diffusion theory which has long been established and applied in various fields, but empirical testing of advanced technology in the field of information relating to subjective norm factors in Theory of Planned Behavior is still difficult to find. This is because almost all research on Innovation Diffusion Theory in information technology midwives is only related to adoption and sustainable use. Empirical testing by Karahana et al. (1999) only to test the construct of Innovation and its effect on subjective norms for potential adopters. However, the effect of the relationship between the two variables is not the focus of research testing.

The findings of this study are theoretically consistent based on the criteria of ISO 9126 meaning that if elearning is easily understood and studied by users, then at the same time Perceived Innovation also meets the criteria of relative excellence compared to conventional learning, Ease of use, and capability to be tested and see the results. In addition, this finding is also in line with the diffusion of Rogers' innovation theory (1983), which states that Ease of use or complexity is one of the reasons for the adoption of innovation, so that in theory it can be said to have a useful relationship between the perceived of influence and innovation. Testing the suitability of the final model reported in this study has accepted a significant relationship between the influence of the usability variable on cognitive absorption. This is theoretically consistent with ISO 9126-1 Theory. The results of this test can be used to explain that when elearning is easily understood and studied by users, the impact will also arouse the mental state of feeling happy, feeling engrossed and continually being motivated to go deeper. So, the results of this test are following the hypothesis that has been formulated.

The results of the final model suitability test have accepted that there is no significant connection between the Perceived Innovation variable on Satisfaction. This test considers that the perceived benefits and perceived Ease of use are part of the Perceived Innovation dimension, so empirical researchers' test results have laid the theoretical foundations for the study of Perceived Innovations affecting the relationship with Satisfaction.

The results of this study are an attempt to fill the empirical gap about perceived innovation on satisfaction. Although the results of this research report are not aligned with the underlying theoretical basis, at 
least it enriches for empirical studies of the theory in question. The findings reported in this study are consistent with the theory used to dismantle the hypotheses in this study. The model of the suitability test results that prove the Influence of even though a small variable Subjective Norms to Perceived of Innovation is the finding that the diffusion process of elearning innovations that occurs due to the Influence of social systems turns out to exist even though there are weak. The findings of this study reinforce Rogers's (1983) diffusion theory which has long been established and implemented in various fields, but empirical testing of advanced technology in the field of information relating to subjective norm factors in Theory of Planned Behavior is still challenging to find.

This finding shows that the elements of e-learning ability to be understood, studied, used, and provide attraction are in harmony with some elements of perceived Innovation such as relative excellence, ease of use, ease of use, trialability and demostrability of results. besides, these findings are also in line with the diffusion of Rogers's (1983) innovation theory, which states that ease of use or complexity is one of the reasons for adoption of innovation so that in theory it can be said to have a beneficial relationship between perceived of influence and innovation.

The final model of the analysis has accepted that there is no significant connection between the Perceived Innovation variable on Satisfaction. Although the test of the influence of perceived innovation on satisfaction based on expectation confirmation theory in the context of information technology found that perceived of use has a direct influence on satisfaction, as done by Bhattacherjee (2001). This test considers that the perceived benefits and perceived ease of use are part of the perceived innovation dimension, so the results of empirical researchers' tests have laid a theoretical foundation for the study of understood innovations that affects the relationship with satisfaction. This research is an attempt to fill the empirical gap about perceived innovation about satisfaction. Although the results of this research report are not aligned with the underlying theoretical basis, at least it enriches empirical studies of the theory in question.

\section{References}

Bhattacherjee, A. (2001). Understanding information systems continuance: an expectation-confirmation model. MIS Quarterly, 25(3)351-370.

Bhattacherjee, A. (2000). Acceptance of internet applications services: the case of electronic Brokerages. IEEE Transactions on systems, Man, and Cybernetics-Part A: Systems and Humans, 30(1) 411-420.

Bhattacherjee, A., (2001). An empirical analysis of the antecedents of electronic commerce service continuance, Decision Support Systems, 2(1) 201214.

Brown, T.J. (2002). Individual and technological factors affecting perceived ease of use of web-based learning technologies in developing country. The Electronic Journal on Information Systems in Developing Countries, 9(5), 1-15.
Butler, D. L., \& Sellbom, M. (2002). Barriers to adopting technology. Educause Quarterly, 2(1) 2228.

Chau, Y. K. \& Hu, P.J. (2001). Information technology acceptance by individual professionals: a model comparation approach. Decision Sciences, 32(1)699700.

DeLone, W. H. \& McLean, E.R. (2003). The DeLone and McLean Model of information systems success: a ten - year update. Journal of Management Information Systems, 19(4) 9-30.

Delone, W.H. \& McLean, E.R., (1992). Information systems success. The quest for the dependent variable. Information Systems Research, 3(1) 60-95.

Fishbein, M., \& Aizen, I. (1976). Misconceptions about the Fishbein model: Reflections on a study by Songer-Nocks. Journal of Experimental Social Psychology, 12(6), 579-584.

Karahanna, E., Straub, D.W., \& Chervany, N.L. (1999). Information technology adoption across time: a cross-sectional comparison of pre-adoption and post-adoption beliefs. MIS Quarterly, 23(2)183-213.

Keil, M., Beranek, P., \& Konsynski, B. (1995). Usefulness and ease of use: field study evidence regarding task considerations. Decision Support Systems, 13(1)75-91.

Kirkpatrick, D. L. (1998). Evaluating Training Programs: The Four Levels. San Francisco: BerrettKoehler Publisher, Inc.

Kumar, V. K., Pekala, R. J., \& Cummings, J. (1996). Trait factors, state effects, and hypnotizability. International Journal of Clinical and Experimental Hypnosis, 1(3) 232-259.

Oliver, R.L., Bearden, W.O. (1985). Disconfirmation processes and consumer evaluations in product usage. Journal of Business Research, 13(1) 235-246

Rogers, E.M. and Floyd, S.F. (1971). Communication of Innovation. New York: Macmillan. Publishing.

Wulf, K. (1996). Training via the Internet: Where are We? Training and Development, 50(5). 